\title{
Outsourcing Provider Selection Model in Public Sector
}

\author{
Glory Urekwere Orlu ${ }^{1}$, Noraini Che $\mathrm{Pa}^{2}$, Rodziah Binti Atan ${ }^{3}$, Hazlina Bt Hamdan ${ }^{4}$ \\ 1,2,3 Department of Software Engineering and Information Systems, Faculty of Computer Science and Information \\ Technology, Universiti Putra Malaysia, Serdang, Selangor, Malaysia \\ ${ }^{4}$ Department of Computer Science, Faculty of Computer Science and Information Technology, Universiti Putra \\ Malaysia, Serdang, Selangor, Malaysia \\ *Corresponding author: ${ }^{*}$ glory_urekwere@yahoo.com, ${ }^{2 *}$ norainip@upm.edu.my, ${ }^{3}$ rodziah@upm.edu.my, \\ ${ }^{4}$ hazlina@upm.edu.my \\ *ORCID ID: https://orcid.org/0000-0002-5271-8570, https://orcid.org/0000-0002-7466-5940*, \\ https://orcid.org/0000-0003-2655-7280, https://orcid.org/0000-0003-1271-4257
}

Article History: Received: 10 November 2020; Revised: 12 January 2021; Accepted: 27 January 2021; Published online: 05 April 2021

\begin{abstract}
In recent times, decision outsourcing IT activities in the public sector is fast evolving in the world at large. This fact has been considered as a high level of strategic measure used in different industries particularly in the public sector where internal IT expertise is found wanting in the area of implementing IT activities to improve the performance growth of the public sector. Although outsourcing IT activities are beneficial to IT Practitioners, Decision-makers, and heads of departments, but the fact remains that choosing the right IT Provider is still a challenge that is inevitable to be avoided as they continue to make the mistake of choosing the wrong IT Provider during outsourcing provider selection. This study considered mainly the approach undertaken towards achieving the key objective of this paper which is the development of the proposed model that can support IT practitioners in outsourcing selection practices. However, this paper considered an appropriate technique that can be implemented in an uncertain and complex situation. Having reviewed thoroughly five existing techniques used in the prior researchers' work, in-depth understanding on this justified that, fuzzy logic and its particular tools used Fuzzy Inference Systems (FIS) was found to be considered efficient and suitable for outsourcing selection practices in an uncertain and complex situation. Also, a pilot study and empirical study were conducted to ascertain the validity of the instruments (questionnaire data). The pilot study consists of 33 respondents while the empirical study consists of 133 respondents. Finally, the reliability test was carried out to determine the validity and reliability of the six influential factors selected, thereafter the proposed model was developed. The application of the developed Decision Outsourcing Selection Model (DOSM) will aid the IT Practitioners in their decision outsourcing Selection practices.
\end{abstract}

Keywords: Decision-making, IT Outsourcing Practices, Outsourcing Selection Model, Public Sector, Selecting IT Provider

\section{Introduction}

For the past decades, outsourcing activities have remained the most important strategy used to promote performance growth in the public sector. Outsourcing is the act of transferring work from one entity to another (1). Prior studies proved that this structure had been in existence for decades in various organizations $(2,3)$. Nowadays, outsourcing activities have eventually filled the gap in how Information Technology (IT) activities can be executed without distracting the assigned professional core activities. This challenge that emanates as a result of lack of internal expertise to handle IT activities (software development) amongst decision-makers, IT practitioners, and heads of departments in the public sector is gradually becoming thing of the past as outsourcing activities continue to come into play (4). No doubt recent studies also indicated outsourcing activities in the public sector is highly beneficial for decision-makers, IT practitioners, and heads of departments as it allows them to fully concentrate on their assigned professional activities rather than wasting time on activities that are unrelated to their expertise which may invariably affect their stipulated strategic objectives $(5$, 6). However, researches have proven the challenge still faced by IT practitioners who could not avoid selecting the wrong IT provider during the outsourcing selection process due to uncertain situations faced in human perceptions or assessment in decision making $(7,8,9)$. In this regard, this study proposed a decision outsourcing selection model (DOSM) to ensure the smoothness and easy practices of IT practitioners in decision making during the outsourcing provider selection process in the public sector. This leads to the main purpose of this paper which is to propose decision outsourcing selection model practices that can support IT Practitioners in selecting the right IT provider for their stipulated project. Also, this paper presents an in-depth understanding of the proposed model for outsourcing selection practices.

Prior researches have proven the need for implementing the proposed model is essential to prevent the occurrence of selecting inappropriate IT providers $(10,11,12)$. The remainder of this paper is organized as follows: In section 2, describes the research focus on decision outsourcing selection model practices, reasons for outsourcing selection model practices, techniques for decision outsourcing selection practices, and the highlight of the technique used in a complex situation while section 3 describes the research method. In section 4 detailed 
descriptions of the proposed model were given as well as results and findings. The final section 5 concludes this paper.

\section{Literature Review}

\section{Outsourcing Selection Models}

(10) proposed Decision-support model for the outsourcing of IT-projects in the public sector to support IT practitioners for quality selection and implementation of IT outsourcing in their evaluation and selection processes using Analytic Hierarchy Process (AHP) technique. The model presents the best outsourcing methodologies consists of qualitative and quantitative criteria that aid in solving the situation in selection and evaluation within the public sector domain. Also, the model consists of eight factors such as Costs, Competencies, Quality, Customer Satisfaction, Risk, Organization, Development, and Innovation used to evaluate and ascertain the best provider selection. The model covers the four main categories such as financial, organizational, developmental, and human resources, and was adapted for public sectors towards enhancing the public interests and socio-economic role of the public sector. The model was able to solve the challenges faced in the public sector on outsourcing selection, however, the model has some limitations towards the selection of criteria (the model does not represent a universal solution) and weighting. A survey was conducted using structured questionnaires and the result proves that outsourcing cannot negatively affect the organization and its human resources.

Finally, the model can assist in the allocation of project management resources and enhance decision making as well as reduce risk in the implementation of outsourcing projects. Notwithstanding some limitations, which can be seen mainly in the traditional way of selection of the criteria and their weighting, such decision-support models should become a standard in the operating and decision-making procedures in the public sector (10). (21) presented the processes of IT outsourcing that are divided into seven phases such as IT demand, Application status and performance evaluation of department; Development and programming of IT; Outsourcing strategies; Design contract object; Select outsourcing providers; Contract negotiation, Implement and supervise; Project approval and proposed an outsourcing fuzzy linear programming model for IT outsourcing provider selection. The model helps in ranking the providers respectively. Also, the model consists of six factors such as Development Capability, Product Quality, Technological Level, Flexibility, Delivery Time, and Price used for evaluating the outsourcing providers. The proposed model supports solving issues in IT outsourcing selection in various aspects such as risk investment, performance evaluation of enterprises, and engineering management. Case research was used to ascertain the model's applicability in practice. However, the author developed a Decision Support System (DSS) using the proposed method TOPSIS as well as a fuzzy set and applied it in the IT outsourcing provider selection processes. There is still a limitation that might require future investigation on DSS towards heterogeneous Multi-attribute Group Decision Making (MAGDM) problems, (21), (9) proposed a Third-Party Logistics (3PL) Vendor Evaluation and Selection Model and suggested a combined approach of Data Envelopment Analysis (DEA), Technique for Order of Preference by similarity to Ideal Solution (TOPSIS) and Linear Programming (LP) problem used to develop a new model for the selection of the 3PL vendor. The model aids in evaluating and selecting the best 3PL service provider. The model provides selection through the performance values of each provider on particular predefined criteria. To prove the applicability of the model in practice, case research was used for justification and the model was finally tested with real-time industry data for 3PL provider evaluation and selection. The processes involved in this research comprise evaluating, selecting, and ranking methods. However, this research has limitations on the exclusion of qualitative criteria for 3PL provider selection and the judgment of weights for TOPSIS.

\section{Reasons for Proposing Outsourcing Selection Model}

As earlier stated prior researches have shown that implementing outsourcing selection models for outsourcing selection is imperative to prevent the occurrence of selecting inappropriate IT providers $(10,11,12)$. Several techniques have been applied to implement such selection models. However, such models have not been able to achieve the strategic goals for outsourcing selection (13), (14), (9,2), (15), (16). To date, adequate decision outsourcing selection model usage has not been prioritized in the public sector $(17,18,19)$. (19) emphasized that the challenge faced by IT practitioners in IT outsourcing organization is the difficulty to outsource to the right IT provider. Hence, (20) stressed that the selection of an IT provider is a complicated decision among IT practitioners since it requires to consider various factors throughout the decision making process. After undertaken several reviews on the existing works, this study identified six influential factors such as; Development Capability (DC), Product Quality (PQ), Time Delivery (TD), Costs (CT), Client Satisfaction (CS), and Service Quality. 
Table 1 summarized the nine existing outsourcing selection models reviewed in this study. The nine models are reviewed in relation to the model's process and technique, problem solved in the researcher's work, and limitation in the model process or approach. The nine models in table 1 proved the fact that there is a need for the proposed model in this study since the existing models still have limitations affecting the effectiveness of selecting the right provider during the decision outsourcing selection process in the public sector.

Table 1. Outsourcing Selection Models

\begin{tabular}{llllll}
\hline No & Model & Authors & Process \& Technique & Problem Solved & Limitation \\
\hline 1 & Supplier & $(14)$ & Process: identification of & Used to evaluate & There was no \\
& selection & & provider selection criteria, and measure & analysis executed to \\
& model & & $\begin{array}{l}\text { evaluation and ranking providers } \\
\text { providers. }\end{array}$ & verify the model. \\
& & & & performance.
\end{tabular}

$2 \quad$ Fuzzy ranking supplier selection model.
Technique: Fuzzy Logic for ranking.

Process: Deduction process is carried using a literature survey.

\section{Technique:}

Fuzzy Logic for ranking.

Process:

Evaluating, selecting and ranking method.

\section{Technique:} TOPSIS.

A hybrid decision

Model.

5 A hybrid

decision

Model.

6 Evaluation

Model.

7 Decision-

\section{Process:}

Evaluating, selecting and ranking method.

Technique: (DEMATEL) method, fuzzy preference programming and the Analytic Network Process (ANP).

Process:

Evaluating and selection.

\section{Technique:}

\section{Fuzzy}

programming and the

Analytic Network Process (ANP).

Process:

Evaluation and selection.

Technique:

ANP.

Process:
For selection Increase in variables criteria indicate incorrect and providers' results and IT performance practitioners need extra efforts towards enhancing compatibility with providers for effective outsourcing activities in author's model.

Used for testing Their model do not data for 3PL have limitation to vendor execute many evaluation and providers however, selection. it consumes time since ranking process are repeated for each provider rank.

Used for Authors' studies are outsourcing limited to multiple provider criteria as it generate selections. different results.

Used for The authors' model selection of calculations rely on partners the decision makers outsourcing experience and providers. knowledge.

Used to handle Their model cannot decision making aid in evaluating and in complex ranking providers situation. process.

Used to solve the The author's model 


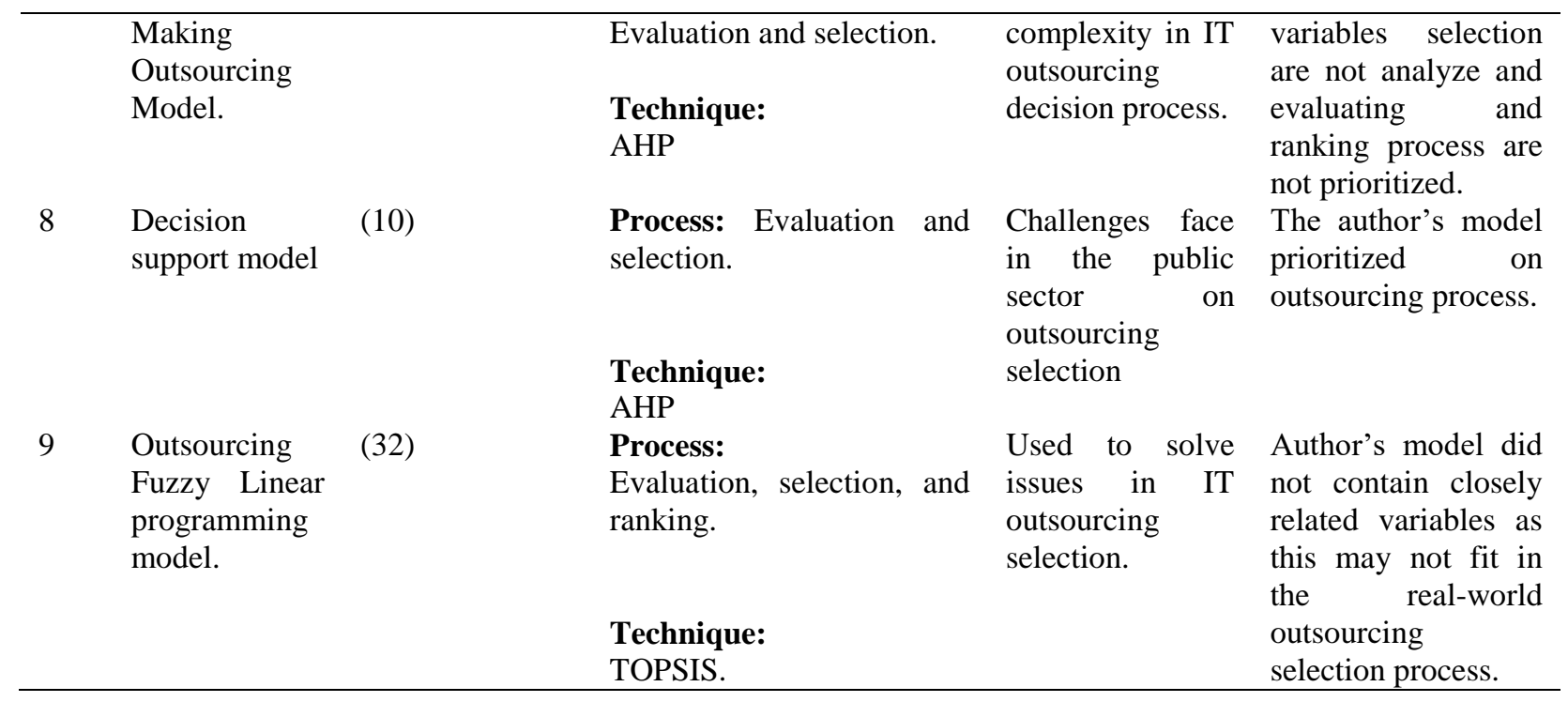

\section{Decision Techniques}

Several studies discussed on MCDM $(16,10),(22),(23)$ noted that making guided decisions poses a serious challenge to decision-makers, IT practitioners, and heads of departments since there are so many options available. Such problems can be best described as Multi-criteria decision making (MCDM) problems. According to (7), problems could arise in the course of decision making for outsourcing selection because of the need to carefully decide while considering diverse opinions and multiple criteria and opinions which increase the complexity of selection. On this subject, (8) studied an MCDM problem that considers the decision maker's choice as a basis for making the preferred decision. Their proposed method applies for triangular fuzzy numbers and employs the Technique for Order Preference by Similarity to Ideal Solutions (TOPSIS). (22), proposed the use of MCDM methods to handle the risk and uncertainty in decision making. However, most of the proposed methods are based on the fuzzy number which does not effectively handle the risks in decision making as observed in the work carried out in the organization $(14,13)$. Decision making becomes complicated when organizations need to decide based on multiple criteria, opinions, and imprecise parameters (24). To solve such multiple provider selection problems (25) presented a novel interactive solution procedure that combines three well-known fuzzy mathematical models. The study by (16), describes a case study involving the analysis of critical factors for use in public sector implementation. Analytic Hierarchy Process (AHP) is considered as one of the Multi-Criteria Decision Making (MCDM) method that was originally developed by (2), (26). AHP is a method used to derive ratio scales from paired comparisons. AHP allows some little inconsistency in judgment because human is not often consistent. AHP in relation to the Fuzzy AHP method is a method for multi-criteria decision making that aids decision-makers to select a choice between alternatives, while Fuzzy logic is an approach that deals with uncertain data and imprecise knowledge. Decision-makers can take a decision in uncertain situations, through the application of Fuzzy $\operatorname{AHP}(27,28)$. Studies from various industries (such as the software industry, construction industry, and logistics and transportation industry) have identified factors that affect decision outsourcing selection and (26) proposed a decision model known as the Analytic Hierarchy Process (AHP) method. (10) identified that outsourcing service to personnel is a problem in the public sector. To address this problem, they deploy a multi-criteria decision-support model based on the Analytic Hierarchy Process (AHP) for enhancing the evaluation, selection, and implementation of IT outsourcing mechanisms in the public sector. In the studies by (29) service provider selection model was developed using the AHP technique.

The ANP methodology comprises three main steps, namely, pairwise comparisons and local priority vectors weighted super-matrix, and super-matrix formation and transformation. The initial matrices represent the pairwise comparisons, which identify the priorities. Studies by Tang et al. (2013), proposed an Analytic Network Process (ANP) decision-making model to deal with the complex relationship between evaluation indicators. The proposed model was used in a case study for outsourcing provider selections.

TOPSIS is based on the concept that the chosen alternative (26). Studies by (9) suggest Third-Party Logistics (3PL) provider evaluation and selection model. TOPSIS was used for evaluating, selecting, and ranking methods. 
The fuzzy logic (FL) technique is considered as an approach to computing based on "degrees of truth" rather than the usual "true or false" (1 or 0 ), Boolean logic on which the modern computer is based. Researches reviewed in the 1960s the concept of fuzzy logic was identified. A fuzzy idea is an idea of which the boundaries of application can vary according to context or conditions, rather than being considerably fixed once and for all. This means the idea or concept is vague in some ways, lacking a fixed, imprecise meaning, without yet being unclear as well as meaningless altogether. Also, Fuzzy logic is a sort of computer logic that is different from boolean algebra founded by Zadeh. FL is different in such a way values are more accurate than on or off. While boolean logic is deemed to be true or false, fuzzy logic allows all things in between. The Fuzzy Logic Technique is used to provide an intelligible description of some complicated factors such as impreciseness, complexity, fuzziness, uncertainty, and vagueness which affect decision making (30). Also, a significant challenge is that human perception, judgment, intuition, and preference remain vague and difficult to measure (31).

\section{A highlight of Technique Used in Complex Situation}

Considering the five techniques such as MCDM, AHP, ANP, TOPSIS, and Fuzzy Logic reviewed in this study, it is obvious even though lots of studies have been undertaken by many researchers towards the usage of the techniques in the outsourcing provider selection process still not all the aforementioned techniques can solve the challenge faced by IT practitioners during the decision making outsourcing provider selection process. This is due to the process for IT provider selection is beyond human perception or the decision maker's intuition, knowledge, and experience.

(1) suggested that not all problems have the same characteristics, neither do they make use of the same data type. This is because some data are intangible, hence others are not, some are qualitative while others are invariably quantitative, some are objective while others are subjective, and some data are conflicting while others are not. The same applies to MCDM methods.

MCDM technique reviewed by (1) not all methods can manipulate all types of information hence the choice of method is determined based on the characteristics of the individual problem and the type of data presented.

AHP technique reviewed by (33) stressed that AHP is easy to use. However, it cannot be taken into account in terms of imprecise values and uncertainties in measuring the performance of the IT provider selection process. Also, (34) emphasized in regards to the fact that human judgment-based factors often entail subjectivity and ambiguity hence the AHP method is not adequately considered as a suitable selection.

ANP technique reviewed by (35) emphasized the major weakness with the ANP technique is that it considers the problem as a unidirectional (operation is allowed in one direction only) problem, however in a real-time situation it is not so. Other shortcomings of ANP includes rank reversal and difficulty in accepting many candidates due to increased complexity and tediousness of computation (35).

The TOPSIS technique reviewed by several studies reviewed by (36), (7) stated that the TOPSIS method could be better if results produced would be able to consider uncertainty and impreciseness instead of crisp values.

The fuzzy logic technique reviewed by (1) identified that fuzzy logic is an effective tool that could solve problems associated with vagueness but the rules on which it is based must be considered consistently and without exception. Also, (37) attested in regards to measuring the applicability of the proposed model; thorough analysis was performed, and consideration of fuzzy environment signifies the involvement of uncertainty and vagueness of the decision-makers that makes the flexibility of this approach possible.

\section{Research Methodology}

This paper undertakes investigation into two phases such as Empirical study and Model development. based on this, some activities were executed such as Pilot Study, Empirical Study, Data Analysis \& Proposed Model. The proposed is describes as Decision Outsourcing Selection Model (DOSM) that aids the outsourcing practices of IT practitioners for selecting appropriate IT providers in public sector.

\section{Phase 1: Empirical Study}

This phase aims to carry out an empirical study basically for IT practitioners that deals on outsourcing selection practices in public sector. The phase consists of a pilot study, empirical study, and data analysis. The 
activities executed in phase 1 describes the steps taken to achieve the model development in phase 2 . The three activities carried out in this phase are described below.

Pilot Study: A pilot study was conducted using a quantitative method to validate the instruments considered. Questionnaires were also administered to IT practitioners. They were asked to express themselves on how they feel about the questions with regard to being in line with their IT practices. Their responses positively indicated that the factors of the research are supportive of their IT practices. However, the answers provided to the methodology questions show that they are only concerned with evaluating their IT providers based on their selected criteria. Hence, methodology concerning how IT providers development the intended project is not necessary. It is interesting to note that three IT experts from three different IT outsourcing organizations gave similar responses to the questions on outsourcing selection practices. Having discussed with these 3 IT experts, it became obvious that their outsourcing selection practices are not consistent because sometimes, they experience a delivery delay from their outsourced IT providers. Finally, the questionnaires were distributed to 50 IT practitioners in various public sectors and they were quested to answer the questionnaires within a 10 minutes. Thereafter, questionnaires were gathered together, only 33 respondents' data were considered valid because their responses are closely related to the objective of this study. Afterward, the required descriptive analysis and reliability analysis were performed respectively.

Empirical Study: Quantitative research methods were conducted to assess and test the relationship between different factors. The survey questionnaires were distributed to all levels of decision makers or IT practitioners which corresponds to 160 respondents in total. 15 questionnaires were received back unanswered. During the evaluation of the questionnaire, 12 questionnaires were deleted because some questionnaire questions were not answered. The total valid answered questionnaires were 133 which indicates a positive response rate for outsourcing selection practices.

In line with this, this study focuses on the decision making processes associated with the selection of software development providers when outsourcing projects in public sector. A decision outsourcing selection model is developed in this respect.

Data Analysis: Quantitative survey research methods were conducted to assess and test the relationship between different factors. A quantitative research is simply the collection of numerical data that will be analyzed using mathematical-based statistical procedures (38).

Data analysis is a method by which the information collected is categorized into groups and analyzed while solving the problem identified in the research (39). SPSS statistical package was used to analyze the quantitative data collected in this study.

\section{Phase 2: Model Development}

This phase aims to develop a model for decision-making in outsourcing software development providers for the public sector. The activities executed in phase 1 aids to describe the steps taken to achieve the development of the Decision Outsourcing Selection Model (DOSM) for IT practitioners in the public sector as shown in figure 1 .

\section{Descriptions of the Models}

The nine existing models reviewed concerning the model's factors, process and technique, problem solved in the researchers work, and limitation in the model process or approach. The nine models such as 1) Supplier selection model by (14) 2) Fuzzy ranking supplier selection model by (13) 3) 3PL vendor evaluation and selection model by (9) 4) A hybrid decision model by (2) 5) A hybrid Multiple Criteria Decision-Making (MCDM) model by (15) 6) Evaluation model by (16) 7) Decision-making outsourcing model by (21) 8) Decision support model by (10) and 9) Outsourcing fuzzy linear programming model by (32). Based on this review, there is a need for the proposed model in this study since the existing models still have limitations affecting the effectiveness of selecting the right provider during the decision outsourcing selection process in the public sector.

\section{Proposed Model}

In this study, a decision outsourcing selection model is developed. As earlier mentioned, the model consists of six components identified as the influential factors such as Development Capability (DC), Product Quality 
(PQ), Delivery Time (DT), Cost (CT), Client Satisfaction (CS), and Service Quality (SQ). It also includes three Decision Outsourcing Selection Processes (DOSP) that are Planning Selection for Providers (PSPs), Evaluating Providers (EPs), and Ranking Providers (RPs) seen in Figure 1.

\section{Description of the Model Components}

The proposed model displayed in figure 1 consists of six influential factors as earlier mentioned, three processes, and output for outsourcing provider selection process in the public sector. The Factors and processes are considered reliable, valid, and correlated based on the final study and data analysis executed for the model development as seen in table 2. The influential factors selected in this paper are presented below;

Development Capability (DC): In development capability, according to (7) IT practitioners investigate IT provider's outsourcing practices based on achieving their strategic objectives goals before taking decisive measures on outsourcing provider selection in the public sector.

Product Quality (PQ): In product quality enhances productivity as well as promoting sustainability and consistency in decision making the demand for outsourcing selection (13).

Delivery Time (DT): In delivery time deals on provider's service delivery-time interval (18), (32), in respect to this fact, IT practitioners ensure absolute efforts are put in place towards meeting their outsourcing milestone which attracts the evaluation of the IT provider's delivery-time interval as a necessity towards achieving their strategic objective goals.

Costs (CT): In costs, reduction aims as the main key factor decision making outsourcing provider selection is practiced by decision-makers, IT practitioners, and IT staff in various organizations (4).

Clients Satisfaction (CS): In clients' satisfaction indicates positive feedback received which proves services rendered meet customers' expectation; it's a means of improving customers' satisfaction (4).

Service Quality (SQ): In-service quality IT providers ensure quality service with cost reduction (7) and the public sector considered delivery time and maintaining quality consistent services in outsourcing provider selection as high priority to achieving.

Also, the proposed model involves three processes for its applicability by IT practitioners such as:

Planning Selection for Providers - Assign Weightage Process: In this process, not more than 100 percent weightage is highly required and assigned to each factor. This is based on IT practitioners' decisions concerning their consideration of each factor's importance, weightage is assigned respectively.

Evaluating Providers Process: In this process, IT providers are evaluated by IT practitioners based on the factors provided with their services rendered.

Ranking Providers: In this process, IT providers' scores value are systematically ranked based on the evaluation results obtained. Finally, the decision for provider selection is achieved based on the systematic rank executed towards the IT provider. Hence, the right IT provider is selected based on the highest score obtained in the ranking process.

\section{Reliability Test}

Both reliability and validity tests are used in this study. As earlier mentioned, the reliability test was conducted based on data obtained from the pilot study. Cronbach's alpha technique was used to achieve the reliability and creditability of the pilot study results as shown in Table 2. This was applied to measure the reliability of the questionnaire adopted for this study. The closer the Cronbach's alpha coefficient value to 1.0, the greater the internal consistency of the items in the scale.

The summary of the reliability results statistics shown in Table 3 indicates a Cronbach's alpha value of .945, with a total of 7 items comprising six independent factors. The decision outsourcing selection process (known as the dependent variable) in the model reveals that the instruments (i.e., questionnaires) used in this study have adequate reliability and are suitable for the study. 
Table 2. Reliability Analysis

\begin{tabular}{lll}
\hline Scale & Cronbach's Alpha & No. of Items \\
\hline Development Capability & .942 & 7 \\
Product Quality & .935 & 11 \\
Delivery Time & .937 & 3 \\
Costs & .941 & 9 \\
Client's Satisfaction & .932 & 6 \\
Service Quality & .933 & 5 \\
Decision Outsourcing Selection Processes & .937 & 24 \\
\hline
\end{tabular}

Table 3. Summary Results Statistics

\begin{tabular}{ll}
\hline Cronbach's Alpha & No. of Items \\
\hline .945 & 7 \\
\hline
\end{tabular}

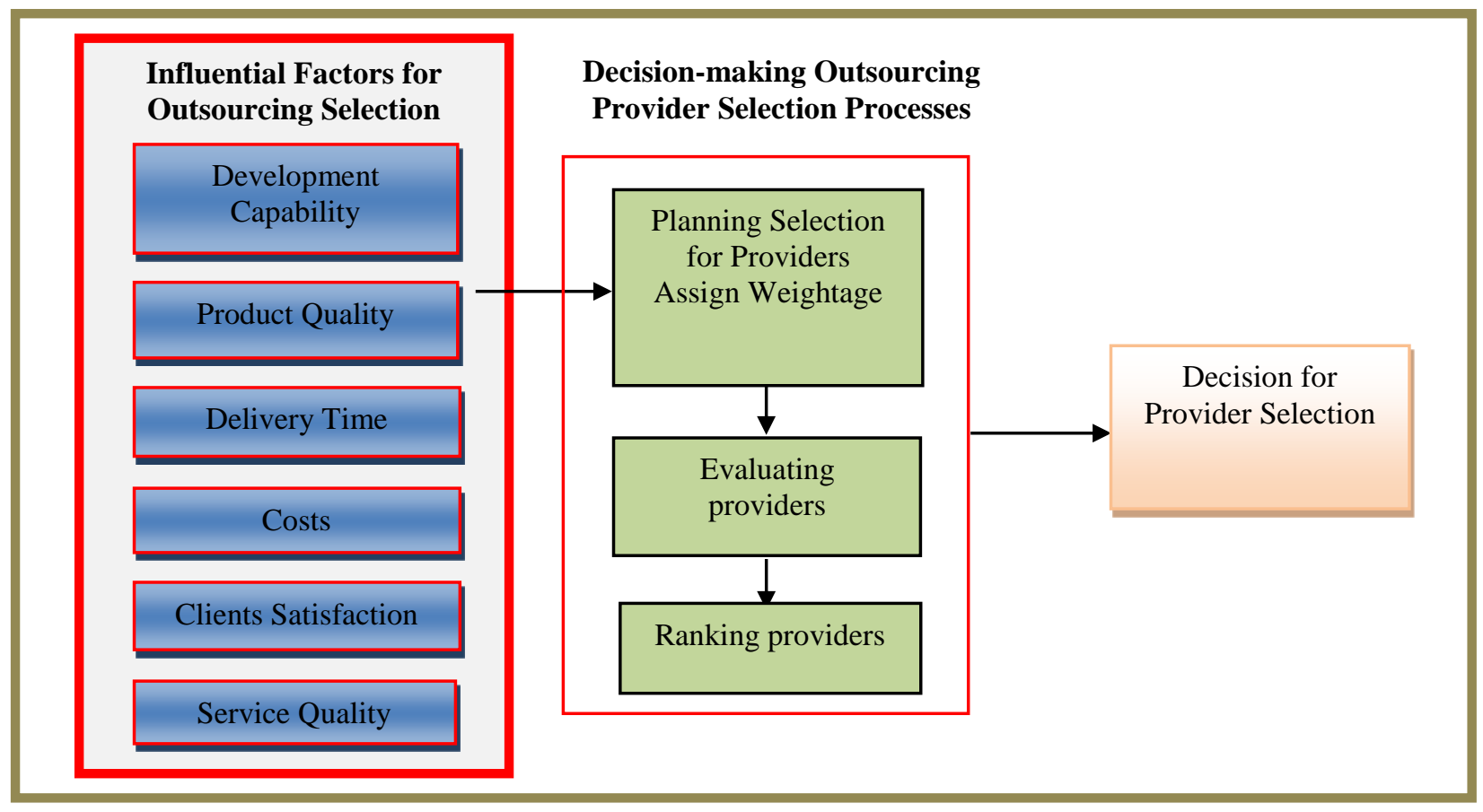

Figure 1. Decision Outsourcing Selection Model

\section{Conclusion, Limitation and Future Work}

The main purpose for outsourcing provider selection today is still not achieved (37) since IT practitioners still could not avoid selecting the wrong IT provider during the outsourcing selection process due to uncertain situations faced in human perceptions or assessment in decision making $(7,8,9)$. In this regard, the proposed model was developed to ensure the smoothness and easy practices of IT practitioners in decision making during the outsourcing provider selection process in the public sector.

Also, the Fuzzy Logic technique used for describing impreciseness and vagueness in decision outsourcing selection was presented. Consequently, this review identified the research gap for this study. Findings from the investigation undertaken on the existing outsourcing selection models show that based on the nine models reviewed in this study, it was observed that the existing models have contributed to the proposed model in the sense that, firstly, this research was able to observe that implementing outsourcing selection models for outsourcing selection in the public sector is essential because it aids to avoid the occurrence of selecting wrong IT providers. Secondly, IT practitioners can have an easy outsourcing selection process since the proposed model identified influential factors concerning the existing model and this aids in having a smooth outsourcing selection process. Thirdly, the existing models helped to identify that factors are used for outsourcing providers' selection project based on the current situation or problems. Fourthly, the existing models have different approaches used in implementing the outsourcing providers selection process hence these support the proposed model in terms of identifying a suitable approach that can aid IT practitioners in making a decision in uncertain conditions. However, this study has a limitation which is related to the selected influential factors in the proposed 
model as future research will require using the proposed model to ascertain existing practices of IT practitioners only in public sectors in Malaysia. Hence findings from this study cannot be generalized to other countries. In future work, the selected factors in the proposed model will be increased to support other countries outsourcing selection practices.

\section{References}

1. Bajec P, Jakomin I. A Make-or-buy Decision Process for Outsourcing. PROMET - Traffic \& Transportation. 2010; 22(4):285-291.

2. Liou J, Wang H, Hsu C, Yin S. A hybrid model for selection of an outsourcing provider. Applied Mathematical Modelling. 2011; 35(10):5121-5133.

3. Li LE. Study of the decision-making model of outsourcing service provider selection. Int. J. u-and e-Service. 2013; 6(2):43-52.

4. Wibisono I, YW, Govindaraju R, Irianto D, Sudirman D. Interaction capability, process quality, and outsourcing success: A vendor perspective in offshore IT outsourcing. Manag. 2016; IEEE Int. Conf. 1780-1784.

5. Oeser G. Segmenting logistics service users based on their provider selection criteria to succeed in outsourcing. Int. J. Retail Distrib. Manag. 2020.

6. Taponen K, Kauppi S. Service outsourcing decisions-a process framework. J. Glob. Oper. Strateg. Sourc. 2020.

7. Senthil A, Srirangacharyulu S, Ramesh B. A robust hybrid multi-criteria decision making methodology for contractor evaluation and selection in third-party reverse logistics. Expert Syst. 2014;41(1):50-58.

8. Zakeri M, Keramati A. Systematic combination of fuzzy and grey numbers for supplier selection Problem. Theory Appl. 2015;5(3):313-343.

9. Haldar SJ, Qamaruddin A, Raut U, Kamble S, Kharat M, Kamble G. 3PL evaluation and selection using integrated analytical modeling. J. Model. Manag. 2017;12(2):224-242.

10. Stanimirovic D. Development of a Decision-Support Model for Outsourcing of IT-S. P. Bingulac, On the compatibility of adaptive controllers. Proc. 4th Annu. Allert. Conf. Circuits Syst. Theory, New York. 2013;8-16.

11. Vintar D, Stanimirovic M. Evaluation of impact of outsourcing on efficiency of public sector organizations. Int. J. Bus. Manag. Stud. 2011;2(3):211-225.

12. Nazim IR, Yaacob R, Ahmad I. Criteria for supplier selection: An application of AHP-SCOR integrated model (ASIM). Int. J. Supply Chain Manag. 2017; (6) 3:284-290.

13. Amindoust A, Ahmed, Saghafinia A, Bahreininejad S. Sustainable supplier selection: A ranking model based on fuzzy inference system." 2012;12(6):1668-1677.

14. Ordoobadi SM. Development of a supplier selection model using fuzzy logic. Emerald. 2009;14(4):314-327.

15. Fadavi M, Asli K. Hybrid Model for Supplier Selection in Outsourcing: Evidence from Shima Film Company in Iran. Res. J. Appl. Sci. Eng. Technol. 2013;5(12):3298-3305.

16. Tang X, Wu Z, Liu Y. Analytic Network Process Model for the Implementation Decision-Making of IT overnance. Int. J. Adv. Comput. Technol. 2013;5(4).

17. Van S, Grembergen W, Haes De. Enterprise governance of information technology: achieving strategic alignment and value. Springer Sci. Bus. Media, 2009.

18. Song $\mathrm{CH}$. Deriving and Assessing Strategic Priorities for Outsourcing Partner Selection in Pharmaceutical R\&D: an Approach Using Analytic Hierarchy Process (AHP) Based on 34 Experts' Responses From Korean Pharmaceutical Industry. Springer. 2019;(14):66-75.

19. Sahu SS, Nitin Kumar, Saurav Datta. Fuzzy based appraisement module for 3PL evaluation and selection. Benchmarking An Int. J 2015.

20. Karrapan PJ, Sishange C, Swanepoel M, Kilbourn E. Benchmarking criteria for evaluating thirdparty logistics providers in South Africa. J. Transp. Supply Chain Manag. 2017;11(1):1-10.

21. Li EL. Study of the decision- making model of outsourcing service provider selection. Int. J. u-and e-Service, Sci. Technol. 2013;6(2):43-52.

22. Krohling TT, Souza de. Combining prospect theory and fuzzy numbers to multi-criteria decision making. Expert Syst. Appl. 2012;39(13):11487-11493.

23. Kramer A, Klimpke T, Heinzl L. Outsourcing decisions of small and medium-sized enterprises: A multiple case research approach in the German software industry. 46th Hawaii Int. Conf. Syst. Sci., 2013:4236- 4245. 
24. Pamucar EK, Chatterjee D, Zavadskas K. Assessment of third-party logistics provider using multicriteria decision-making approach based on interval rough numbers. Comput. Ind. Eng. 2019. (127):383-407.

25. Arikan F. An interactive solution approach for multiple objective supplier selection problem with fuzzy parameters. Springer. 2015;(26):989-998.

26. Bianchini A. 3PL provider selection by AHP and TOPSIS methodology. Benchmarking An Int. J. 2018.

27. Hahn NJ, Sens, T, Decouttere C, Vandaele N. A multi-criteria approach to robust outsourcing decision making in stochastic manufacturing systems. Comput. Ind. Eng. 2016;(98):275-288.

28. Awasthi S, Govindan A, Gold A. Multi-tier sustainable global supplier selection using a fuzzy AHP-VIKOR based approach. Int. J. Prod. Econ. 2018;(95):106-117.

29. Wanigasinghe I, Mahakalanda PC. Building services maintenance: an outsource service provider selection via scoring model. 2018.

30. Rashidi K, Cullinane K. A comparison of fuzzy DEA and fuzzy TOPSIS in sustainable supplier selection: Implications for sourcing strategy. 2019;(121):266-281.

31. Foroozesh SM, Tavakkoli-Moghaddam, Mousavi R. Sustainable-supplier selection for manufacturing services: a failure mode and effects analysis model based on interval-valued fuzzy group decision- making. Int. J. Adv. Manuf. Technol. 2018; 95(9-12):3609-3629.

32. Li SP, Wan DF. A fuzzy inhomogenous multi attribute group decision making approach to solve outsourcing provider selection problems. Knowledge-Based Syst. 2014;67:71-89.

33. Luk HY, Choy K, Lam L. Design of an enhanced logistics service provider selection model for ecommerce application. Portland International Conference on Management of Engineering and Technology (PICMET). 2018:1-7.

34. Garg CP. A robust hybrid decision model for evaluation and selection of the strategic alliance partner in the airline industry. J. Air Transp. Manag. 2016;52:(pp. 55-66).

35. Girubha K, Vinodh E, Vimal K. Application of interpretative structural modelling integrated multi criteria decision making methods for sustainable supplier selection. J. Model. Manag. 2016.

36. Prakash MK, Barua C. An analysis of integrated robust hybrid model for third- party reverse logistics partner selection under fuzzy environment. Resources. Resour. Conserv. Recycl. 2016;(108):63-81.

37. Galal H, Mostafa A, Elawady N. Supplier Evaluation and Selection for Logistics Outsourcing: A Conceptual Framework. Ref. 16, 2018.

38. Rossoehme DH. Overview of qualitative research. J. Health Care Chaplain. 2014;20(3):109-122.

39. Grossoehme E, Lipstein D. Analyzing longitudinal qualitative data: the application of trajectory and recurrent cross-sectional approaches. BMC Res. Notes. 2016;9 (1): p. 136. 